\title{
Humanistic Approach in Economic Anthropology: Modern Social and Cultural Context Reflection and Change
}

\author{
Anastasia 0 Ljovkina* \\ University of Tyumen, Russia
}

*Corresponding author: Ljovkina Anastasiya Olegovna, Candidate of Economic Sciences, Associate Professor, Chair of Mathematical Methods, Information Technologies and management systems in the economy, Tyumen State University, 625003, Russian Federation, Tyumen, Russia

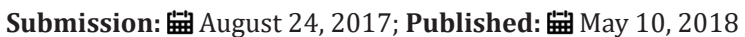

\begin{abstract}
Researches on economic anthropology bring different social benefits depending on their general theoretical background. Taking into account the modern inter-civilization period, characterized by sensitivity of culture to changes, social flexibility, high opportunities of individuals to influence the culture and the scale of today's global civilization problems, we propose the strong necessity of special focusing on human values in economic anthropology research by means of applying humanistic approach as their general ethic-theoretical perspective. The article gives recommendations of designing economic anthropology study in frames of humanistic approach on different stages of research process. Humanization effect of some famous anthropological research on developing economic theory and practice is analyzed. The author believes that applying humanistic approach in economic anthropology will crucially increase social benefit of research for achieving goals of common sustainable prosperity. In conclusion, the article characterizes the desired humanistic focus of economic anthropology research in XXI century.
\end{abstract}

Keywords: Economic anthropology; Sustainable development; Humane society; Social engineering; Ontology of social development

\section{Introduction}

Economic anthropology has always played a crucial role in economic science, providing it with rich empirical and analytical materials on human economic behaviour in historic, cultural and geographic aspects. Given the contemporary civilization crisis, which is noted by many philosophers, economists and experts [1-9] basing upon different ideologies and values, there is a strong need in economic anthropology research, unpacking cultural determination of human behaviour and searching for economic underpinnings of sustainable social development. Being an important factual evidential, explanatory and discursive background of economic and social sciences, economic anthropology challenges abstraction, contextually and implicit assumptions of economic theories and approaches, continuously improving economic methodology.

Our contemporaneity can be characterized as inter-civilization a period when modern culture exists between two different forms defined by sustainable social agreements and accepted norms [10]. In other words, we live in the times of developing the civilization of a new type [11]. In the psychological context, inter-civilization period implies "high sensitivity" of the culture to changes and more flexible social contours. In the terms of natural sciences this period can be defined as a "period of bifurcation", when numerous "points of bifurcation" [12] - moments, situations, when a little purposeful actions sufficiently influence the development of the whole social system- can be created.

Specifics of inter-civilization period and aims of social sustainable prosperity advance a claim of conscious and responsible scientific choices: problem development, critical reflection of implicit assumptions and ethics behind the research methodological basis. To increase social benefit of research for achieving goals of sustainable development and to design the research focusing on the humane values, a scientist can apply humanistic approach as a general prescriptive approach in the research methodological basis.

\section{Humanistic Approach}

Humanistic approach is a methodological approach which allows researchers and practitioners to focus on the humanistic sense of research objects (activities, relationships, and others) and assert the priority of humane values in the research goals and means. The logic of applying this approach in humanitarian sciences is defined by the chosen scientific paradigms (positivism, hermeneutics or activity theory). Humanistic approach implies conscious problem 
formulation in compliance with its meaningfulness for promoting humanity and solving significant social problems. Researchers should ask themselves: "Answers to what questions are needed to promote humanity, contribute to the sustainable development, or understand the deep causes of modern civilization crisis and possibilities of individuals and society to change the world for the better?"

Humanistic approach also presupposes deep semantic and value analysis of investigated phenomena, the ontology and modern epistemological practice of phenomena investigation. In other words, this approach creates ethic and value "lenses" (i.e. supports critical thinking basing on the humane values), orients the researcher in the choice of the research angle, and provides framework for developing adequate methodological basis for the particular research.

Humanistic approach has a close methodological connection with socio-cultural approach which has been developed by Max Weber, Pitirim Sorokin, Aron Gurevich and others and anthrop societal approach [13] methodological approaches basing on the general system, which attempt to investigate the unity of society, culture and personality, and implies that social reality and culture are formed and transformed by the human activity. The latter requires being supported by the activity theory (or activity paradigm), which matches humanistic and socio cultural approaches. Activity theory primarily developed by L. Vygotsky and A. Leont'ev considers common social activity as activities of particular individuals, implies that human personality develops in the process of social activity, and human consciousness develops as a "moment of personality" [13]. At the same time, personal activities are the driver of the social and psychic development of the society. Personality is a creative entity, the generator of innovations which further separate from the personal activity and transform in the cultural facts as components of semiotic sphere [14].

\section{Designing Economic Anthropology Research in Frames of Humanistic Approach}

Regardless of the chosen scientific paradigm basing on humanistic approach, the researcher focuses on the realization of common humane values on the following stages:

1. The choice of the focus of the scientific research. The researcher formulates the object of cognition in a particular scientific paradigm. For example, the researcher in the sphere of economic anthropology can investigate the problem of prosperity on the basis of positivism methodology. However, prosperity can be understood differently depending on the explanatory theoretical basis and researcher's ethical background. The chosen meaning of prosperity will determine the phenomena observation parameters and measurement criteria. Humanistic approach focuses the researcher's attention on the social-economic (not chrematistic) and ecological sense of prosperity, and it tunes a researcher's mind into designing the appropriate system of observation parameters and indicators (such as ecological conditions of environment, opportunities for personal and professional development, education, interesting and socially significant job, health, happiness, collaborative social atmosphere, provision of housing habitation, access to quality medicine and etc.)

2. Designing a structure of scientific research. Structure of a particular scientific research should provide matching and adequacy of using scientific theories approaches and methods for solving research tasks. For example, if a scientist does research in financial anthropology, investigating different monetary systems and their influence on the common prosperity, the method of assessing the results should match the sustainable development goals, i.e. focus on ecological and social economic but not financial effects.

3. Valuation and interpretation of research results. Humanistic approach allows researchers to pay attention to humanistic aspects of research results, revealing obstacles and reserves of the society in achieving the goals of sustainable prosperity. Humanistic approach can also serve as an instrument of extraction of the knowledge of a new quality and a perspective of analysis of the existing economic anthropology research, as well as a basis of developing the system of the analysis parameters and assessment criteria for research results.

4. Valuation of theoretical and practical significance and implications of research results. Basing on humanistic approach, a researcher can assess the extent of significance of the research results, the level of settling the research question (strategic, tactic or operative), and principal conformity of the research design with human values.

\section{Contribution Of Anthropological Analysis to the Development of Humane Society}

Indebted to the economic anthropology research, economic theory is continuously revised and reflected by means of the analysis of historical economic practices, relationships and their consequences. In particular, economic anthropologists propose strong arguments against the concept of "Homo economics" developed by J. S. Mill, A. Smith, D. Ricardo which was widely spread and implemented in economic practice through mathematical toolkit (such as Paretto distribution, Bertrand-Edge worth model of oligopoly, general mathematical theory of political economy of W.S. Jevons, Walras low) in XX century. In the frames of substantives developed by K. Polanyi and culture list approach developed by S. Gudeman, it has been shown that formalist assumption that all human behaviour can be explained in terms of rational decisionmaking and utility maximization is insolvent.

Research on economic anthropology contributes a lot to the deep understanding of the reasons of today's civilization crisis and stimulates social engineering research through showing a high extent of cultural determination of human behaviour, social atmosphere, ecology and common community prosperity by means 
of its fine-grained empirical and analytical toolkit [15-18]. They give us real historical examples of abundance, absence of resource deficit, atmosphere of happiness in communities characterized by collaborative not-market social-economic relationships, environmentally friendly behaviour, absence of artificially formed needs [19-21]. Certifying that "Civilization of leisure" is much closer to the primitive state of humanity than to the modern civilization [19], economic anthropology throws a challenge to the modern economic theory and practice. Healthy psychological atmosphere, cooperation, common prosperity and harmony with nature in communities having relationships of reciprocity (gift exchange) and redistribution (central distribution) encourage scientific discourse on social-economic systems alternative to the market ones.

E. Fromm's analysis of anthropological research of R. Benedict, M. Mead, G. Murdock, and K. Turnbull sufficiently influenced the humanization of social and economic theory, critically revising popular ideas about inherent aggressive and rational human nature."Theory of an innate aggressiveness easily becomes an ideology that helps to soothe the fear of what is to happen and to rationalize the sense of impotence. There are other reasons to prefer this simplistic answer of an instinctive theory to the serious study of the causes of destructiveness. The latter calls for the questioning of the basic premises of current ideology; we are led to analyze the irrationality of our social system and to violate taboos hiding behind dignified words, such as "defence," "honour," and "patriotism." [20]. This is a great example of the humanistic analytic anthropological research, aimed at the search of deep causes of modern social destructive behavior and social-cultural potential to overcome such behavioural destructiveness.

In general, historical-cultural background allowed many researchers to see paradoxes of our time more distinctly and ask important questions, such as: why after working all day at jobs we often dislike, we buy things we don't need? [22] or why having high and ecological technologies and high level of automation which allow to free people from routine work and provide all their rational needs, we still have deficit, wars, environmental crisis and poverty? [23].

And finally, the results of economic anthropology studies provoke serious doubt: whether our society is really civilized and progressive in comparison with primitive communities or it is degrading considering the tendency of human animalization [2426], zombie culture and politics [27], consumer society [1], socialeconomic cannibalism [28-30], and wars caused by the needs of continuous growth of the capital? [31-33].

\section{The Role of the Economic Anthropology in Designing a Future}

Coming to the "point of no return" [34] revealed the need to reconstruct basic social-economic mechanisms, which significantly configure modern cultural and social-economic order and context. Sociocybernetics and social engineering gain popularity, modern social future design goes out of the range of utopias. One of the most famous models of new social-economic systems is a Project "Venus" which is based on the idea of resource-based non-monetary economy [35].The cornerstone of developing this idea was understanding the fundamental causes of contemporary destructive social practices, dysfunctional behaviours, fading humane values and tremendous environmental and social consequences. To find answers, J. Fresco had to make own anthropological research, living on the Tuamotu Islands with a aborigines and analyzing the extent of the social and the cultural in human nature, observing social and economic consequences in the context of other property and economic relationships and impact of resource deficit on human behaviour. He came to a conclusion that cultural context in general, and economy as a system of resource and goods production, exchange and distribution, in particular, have a tremendous influence on the social prosperity and sustainability of community's development. Anthropological factual background helped the researcher to avoid false theoretical implications and axioms and discover that "many of the dysfunctional behaviours of today's society stem directly from the dehumanizing environment of a monetary system" [35].

Famous sociologist T. Veblencritically analyzed property relationships using cultural-historical and humanistic approach and came to a conclusion that private property was becoming a serious limit to human freedom while industrialization processes were developing accompanied with extension of wage labour, ownership of means of production and concentration of wealth[Veblen, 2017a]. Therefore, developing the idea of technocracy, T. Veblen searched for more rational and humanistic alternatives to the market monetary system [36].

The humanistic ideas of T. Veblen, E. Fromm, J. Fresco that stemmed from the anthropological analysis gave a very constructive direction for further theoretical research and practical social transformations, approximating the future of sustainable prosperity.

Given a strong need in developing more effective and sustainable social-economic contours and mechanisms, the social order for experimental economic research is growing on a great scale. Social engineering ideas and experimental economic hypotheses often come from economic anthropology: reciprocity relationships as an alternative to the market [37], principles of centricity, symmetry, and economic self-sufficiency [38], moral economy [39]. Based on this anthropological background, a number of experiments with Guaranteed Annual Income (GAI) have been launched (such as in Dophine, Canada, Denver, USA, New Jersey, USA, Madhja-Pradesh, India, Alaska, USA, 10-years projects of GAI in Kenia, Norway, Switzerland, Finland, Netherlands) [22]. In particular, analysis of economic experiment with implementing GAI showed [40]:

a) Numerous positive synergetic social effects: improving health, positive psychological atmosphere in the community, growing interest to self-education, self-development, improving academic performance in schools, less crime.

b) Spending much more time on socially significant projects. 
c) Unexpected increasing of motivation to work, implying implicit motivation and taking into account growing hours spent on useful social work: taking care of kids, disabled parents, community service, etc.

Basing on the vast analysis of anthropological observations, famous Russian scientist P.A. Kropotkin came to the viewpoint that the law of mutual aid is as natural as the law of mutual struggle, but the first one is far more important for social progressive development than the second one [41]. He researched phenomenon of mutual help in the tribes of Bushmen, khaasen, Eskimos and demonstrated its role in creation of clans and communes as forms of human society. The results of anthropological analysis and humanistic views of the scientist became fundamentals of his further developing the idea of a new social order, which he saw as a free federative union of self-regulated social units (communities, territories and towns) based on principles of free will and absence of power.

The ideas of libertarian communism and anarchism were successfully implemented in Aragon, Spain, in 1936-1939 where both money and power were abolished. Later M. Bookchin analyzed this experience from the humanistic point of view: "anarchism is above all anti-hierarchical rather than simply individualistic; it seeks to remove the domination of human by human, not only the abolition of the state and exploitation by ruling economic classes confederacies was to constitute a moral cement and a source of communal solidarity that transcended a bourgeois egotism based on self- interest [42]. This social-economic experiment (stopped by Spanish dictator regime) still supplies researchers with rich empirical and analytical materials for the development of ideas of a new social order in accordance with humanistic values.

\section{Conclusion}

Topicality of global humanity problems and aims of common sustainable prosperity requires new focus of economic anthropology research in XXI century, consisting in:

a) Analyzing deep causes of "social illnesses" and searching for the reserves of the "healing".

b) Concentrating on the tasks of human civilization vitality (vs. prolonging the vitality of the existing social-economic system).

c) Reflecting on the meanings and values lying behind human behaviour in different cultures and exposing mistakes in the social "operation system" that determines human behaviour "software".

d) Investigating possible contours of the alternative socialeconomic systems and predicting their social-economic consequences.

\section{References}

1. Bodrillard J (1998) The consumer society: myths and structures. Sage Publications Ltd, New York, USA, p. 224.

2. Eagleton T (2015) Culture and the Death of God. Yale University Press, New Haven, US, p. 248.
3. La Rouche LH (2017) Earth's next fifty years: EIR Edition, Independently published, p. 492.

4. Stiglitz JE (2016) The great divide: Unequal Societies and what we can do about them. W.W. Norton \& Company, New-York, USA, p. 464.

5. Lietar B (2011) New money for a new world. Qiterra Press, p. 390.

6. Soros G (1998) The crisis of global capitalism: open society endangered. Public Affairs, New-York, p. 288

7. Korten DC (2015) When corporations rule the world, Berrett-Koehler Publishers, Oakland, USA, p. 424.

8. Spengler 0 (2017) The decline of the west: form and actuality (Classic Reprint, first published in 1918). Forgotten Books, London, UK, p. 488.

9. Katasonov VU (2014) Interest: Loan, Justifiable, Reckless: "The Money Civilization" and the Present-Day Crisis, Parker: Outskirts Press, p. 706.

10. Pavlov AB (2012) Civilization and inter-civilization Era, Gerald of perm university, Russia, 3(11): 17-26.

11. Stjopin VS (2011). Era of Change and Scenatios of the Future, Russia.

12. Prigozhin I, Stengers I (2017) Order out of chaos. Verso, London, UK, p. 349.

13. Lapin NI (2005) Anthrop societal approach: Methodological Basis, Sociological Measurement, Philosophical questions, Russia, pp. 17-29.

14. Leontjev AA (2006) Psychological activity theory. Smysl, Moscow, Russia p. 389.

15. Benedict R (1934) Patterns of culture. Houghton Mifflin company, Boston, US, p. 290.

16. Mead M (1961) Cooperation and competition among Primitive Peoples. Beacon Press, Boston, US, p. 544.

17. Murdock GP (1934) Our Primitive Contemporaries. Macmillan, New York, USA, p. 614 .

18. Turnbull CM (1965) Wayward servants, or the two worlds of the African pygmies. Eyre \& Spolliswoode, London, UK, p. 390

19. Sahlins MD (1972) Stone Age Economics. Aldine-Atherton, Chicago, US, p. 348 .

20. Fromm E (1973) The anatomy of human destructiveness. Holt, Rinehart and Winston, New-York, USA, p. 521.

21. Malinovski B (1979) Ethnography of malinowski: trobriand islands, 1915-18. Routledge \& Kegan Paul Books, London, UK, p. 264.

22. Bergman R (2017) Utopia for Realists: How we can build the ideal world. Little, Brown and Company, Boston, US, p. 336.

23. Fresco J (2002) The Best that money can't buy: beyond politics, poverty, \& war. Global Cyber-Visions, Venus, p. 166.

24. Akerlof GA, Shiller JR (2009) Animal spirits: how human psychology drives the economy. Princeton and Oxford: Princeton University Press, UK, p. 248.

25. Danilenko V (2015) From Animal to Human. Introduction to evolution ethic. LitRes, Moscow, Russia p. 392.

26. Agamben G (1998) Homo sacer: sovereign [ower and bare life. Stanford University Press, Redwood City, US, p. 2016.

27. Giroux HA (2014) Zombie Politics and Culture in the Age of Casino Capitalism: Popular Culture and Everyday Life $\left(2^{\text {nd }}\right.$ edn), Peter Lang Inc., International Academic Publishers, New-York, USA, p. 205.

28. Semjonov UI (2003) Pholosophi of history. General Theory, Basic Problems, Ideas, Concepts from Acency up to Modernity. Modern copybooks, Moscow, Russia, p. 777.

29. Hill CM (2011) Cannibal capitalism: how big business and the feds are ruining america. Wiley, Hoboken, US, p. 256. 
30. http://davidstockmanscontracorner.com/the-essence-of-cronycapitalism-dead-weight-inefficiencies-owing-to-economic-cannibalism

31. Colgan JD (2013) Petro-Aggression: when oil causes war. Cambridge University Press, New York, USA, p. 324

32. Butler SD (2014) War is a Racket: The antiwar Classic by america's most decorated soldier. CreateSpace Independent Publishing Platform, p. 58.

33. Perkins J (2004) Confessions of an economic hit man. First Plume Printing, New York, USA, p. 307.

34. Meadows DH, Meadows DL, Randers J (2004) Limits to growth: The 30year update. Chelsea Green Publishing Co, Hartford , US, p. 338.

35. Fresco J, Meadows R (2016) Designing the Future. ePublishing rights Osmora Publishing, India, p. 76.

36. Veblen T (2017b) The Engineers \& the Price System: From the Author of the theory of the leisure class, the theory of business enterprise, imperial germany and the industrial revolution \& the higher learning in america. Musaicum Books, p. 102
37. Mauss M (1954) The Gift: forms and functions of exchange in archaic societies.:Cohen \& West, London, UK, p. 136.

38. Polanyi K (2001) The great transformation: the political and economic origins of our time ( $2^{\text {nd }}$ edn). Beacon Press, Boston, US, p. 360

39. Scott JC (1977) The moral economy of the peasant: rebellion and subsistence in southeast asia.Yale University Press, New Haven, US, p. 257.

40. Forget EL (2011) The town with no poverty. University of Manitoba, p. 38.

41. Kropotkin P (1915) Mutual Aid. William Heinemann, London, UK.

42. Bookchin M (2015) To Remember Spain: The Anarchist and Syndica list Revolution of 1936. AK Press, Dan-Francisco, US, p. 69.
Creative Commons Attribution 4.0 International License

For possible submissions Click Here

\section{Submit Article}

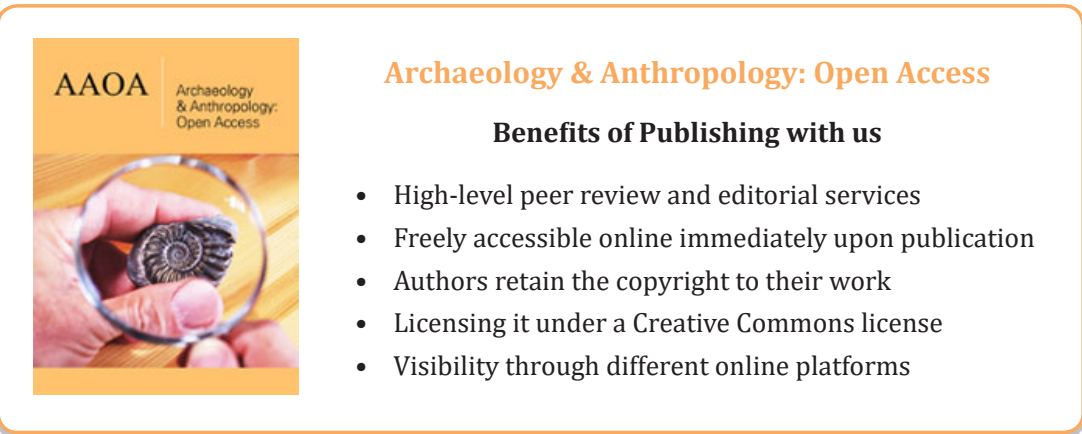

